\title{
Metal binding by dissolved organic matter in hypersaline water: a size fractionation study using different isolation method
}

\author{
Keli Yang ${ }^{1}$, Yaoling Zhang ${ }^{1}$, Yaping Dong ${ }^{1}$, Dongdong $\mathrm{Li}^{1}$, and $\mathrm{Wu} \mathrm{Li}^{1}$ \\ ${ }^{1}$ Qinghai Institute of Saline Lakes Chinese Academy of Sciences
}

July 1,2020

\begin{abstract}
The influence of dissolved organic matter (DOM) on mineral extraction from salt lake brines depend on DOM quality. This study contributes to our knowledge of DOM's metal binding behavior in hypersaline environments by characterization of DOM from lakes in the Qaidam Basin, i.e., Qarhan Lake (LQDOM), Da Qaidam (DQDOM) and West Ginair Salt Lake (WGDOM). The DOM was fractionated based on solid phase extraction (SPE) and ultrafiltration (UF), and the spectral and metal binding behavior of these fractions were studied by absorption spectroscopy, $\mathrm{Pb}$ (II) titration techniques and fluorescence parallel factor (PARAFAC) analysis. The results showed that bulk DOM generally contained more dissolved organic carbon (DOC), lower specific UV absorbance (SUVA254), higher fluorescence and biological indices, comparable humification index, and lower condition stability constants compared to the other nature waters. Compared with UF, SPE-derived DOM exhibited higher DOC recovery and aromaticity and lower carbohydrate yield. It appears that the SPE procedure used affects the spectral composition of bulk DOM to a larger extent than UF. Source and molecular weight (MW)-dependent differences in abundance and quality of brine DOM was indicated by higher SUVA254 in high MW DOM, for LQDOM and DQDOM, and humic-like fluorophores were mainly in high MW-DOM in each lake. Moreover, the high MW humic-like component exhibited higher metal binding potential than the bulk and low MW counterparts for LQDOM and DQDOM, while the inverse was observed for WGDOM. This study revealed the effects of isolation techniques on interpretation of DOM characteristics, and meanwhile highlighted the importance of origin- and MW-dependent DOM in manipulating the behavior, fate, and bioavailability of heavy metals in salt lake brine.
\end{abstract}

\section{Introduction}

Salt lake brines are unique natural waters that widespread over the Earth's surface. They often contain significant amounts of mineral resources such as lithium, boron, and halite(Zheng, 2011). Therefore, salt lake brines are considered a resource of mineral salts. In addition to inorganic components, salt lake brines contain dissolved organic matter (DOM). Now that the scale of development and exploitation of salt lakes is expanding rapidly in the last decade(Peng-Sheng et al., 2011), the influence of DOM on the exploitation of mineral resources (e.g. smells and colors)(Shalev, Lazar, Köbberich, Halicz, \& Gavrieli, 2018) and its role on the geochemical cycle of nutrients, carbon and trace metals are investigated(Hosen, Armstrong, \& Palmer, 2018; Jun Wu, Zhang, Yao, Shao, \& He, 2012; Xiping, 2008). Nevertheless, contrary to DOM in other aquatic environments such as freshwater and marine water bodies and their sediments(C. H. Fan, Chang, \& Zhang, 2016; Y. Li et al., 2017; Z. Li et al., 2020; Singh, Inamdar, \& Mitchell, 2015), little research has been performed on DOM from salt lake brines. Therefore, it is essential to study the chemical properties of DOM in salt lake brine and their interactions with inorganic phases, and develop guidelines for resource development and environmental assessment in the future.

The DOM isolation and concentration procedure are important first steps in DOM research in general(Xingjun Fan, Song, \& Peng, 2012; H. Li \& Minor, 2015; E. C. Minor, Swenson, Mattson, \& Oyler, 
2014; Sandron et al., 2015), and even more so for hypersaline environments. Isolation methods applied in desalination of saline waters fall mainly into two categories, i.e. solid phase extraction (SPE) and ultrafiltration (UF)(Dittmar, Koch, Hertkorn, \& Kattner, 2008; Sandron et al., 2015; X. Wang, Goual, \& Colberg, 2012). Different isolation approaches usually yield DOM with different structural properties. For instance, the SPE approach tends to isolate hydrophobic DOM fractions(X. Fan, Song, \& Peng, 2013; Perminova et al., 2014), whereas UF more efficiently retains oxygen-functionalized compounds(Abdulla, Minor, Dias, \& Hatcher, 2010; Hussain A. N. Abdulla, 2010). This is related to the different adsorption and retention mechanism between SPE (mainly based on hydrophobic or hydrophilic interactions between DOM and sorbents) and UF (based on molecular size and shape)(Kruger, Dalzell, \& Minor, 2011). Comparative studies on chemical composition of DOM fractions obtained by different methods is required to obtain unbiased conclusions on structures and properties of DOM from hypersaline water.

In addition to isolation approaches, the MW distribution of DOM is an important factor. Xu et. al. (H. Xu, Zou, Guan, Li, \& Jiang, 2019) observed that fulvic- and humic-like DOM from sediments were mainly in the low MW fraction (LMW), while tyrosine- and tryptophan-like proteins are main part of high MW (HMW) components. Wu et. al. (F. C. Wu \& Tanoue, 2001) found that amino acids in lacustrine DOM were relatively more abundant in the HMW $(>5 \mathrm{kDa})$ than in the LMW fraction $(<5 \mathrm{kDa})$. Regarding binding behavior with trace metals, different MW fractions usually exhibit different binding potentials. For example, HMW ( $>1 \mathrm{kDa})$ DOM generally had higher $\operatorname{logK}$ and binding fluorophore abundance with $\mathrm{Cu}^{2+}$ or $\mathrm{Ca}^{2+}$ than bulk (unfractionated) and LMW ( $<1 \mathrm{kDa})$ DOM for freshwater and sediment DOM(W. Chen, Smith, \& Guéguen, 2013); The opposite result, however, was obtained for vinasse, where the fractions with LMW $(<$ $500 \mathrm{Da}$ ) showed the greatest $\mathrm{Cu}^{2+}$ binding capacity (de Zarruk, Scholer, \& Dudal, 2007). Evidence of DOM MW effect on metal binding affinity was also reported for soil fulvic acid and humic acids, for both $\mathrm{Al}^{3+}$ and $\mathrm{Pb}^{2+}$ (Christl, Milne, Kinniburgh, \& Kretzschmar, 2001; Lakshman, Mills, Patterson, \& Cronan, 1993; Shin, Hong, Lee, Cho, \& Lee, 2001). However, studies on the structure- and MW-dependent interactions between DOM and metals in brine waters are scarce.

Nowadays, spectroscopic techniques such as UV-visible absorption and fluorescence are widely employed for DOM characterization in different aquatic environments(Carstea, Baker, Pavelescu, \& Boomer, 2009; Gueguen \& Cuss, 2011; Sandron et al., 2015). Moreover, fluorescence quenching experiments coupled with excitation-emission matrix (EEM) spectra and parallel factor analysis (PARAFAC) can reveal information on interactions between DOM and trace metals, which will contributable to predict the mobility, fate and toxicity of trace heavy metal ions(Jun Wu et al., 2012; Zhang et al., 2010).

In this study, DOM from salt lake brine with different sources, i.e., Qarhan Lake, Da Qaidam Salt Lake and West Ginair Salt Lake, were fractionated using different isolation procedures (SPE, UF, and bulk DOM). Comparative studies on the spectral properties and composition in different fractions were investigated using dissolved organic carbon (DOC) recovery, UV-visible absorbance, EEM spectra and carbohydrate analysis. Moreover, $\mathrm{Pb}(\mathrm{II})$ was applied as the representative trace heavy metal due to the existence of lead-zinc deposits in the sampling region, whose binding properties with different MW-fractionated samples were investigated using fluorescence quenching titration combined with parallel factor (PARAFAC) analysis. The objectives of this study are (1) to investigate the effects of extraction methods on chemical composition of DOM extracted from hypersaline water, and (2) to explore the MW-dependent heterogeneity of $\mathrm{Pb}(\mathrm{II})$ binding affinities within the DOM fractions using PARAFAC analysis combined with the fluorescence spectra.

\section{Materials and methods}

\section{Sampling sites and description}

The salt lake brine was collected in December 2019 from three the most representative hypersaline lakes, i.e. Lake Qarhan (36deg57'54"N and 95deg14'23" E, chloride type), the largest salt lake in China; Da Qaidam Salt Lake (37deg51'32"N and 95deg15'22"E, sulfate type), and West Ginair Salt Lake (37deg40'53"N and 93deg24'30"E, sulfate type), all located in Qaidam Basin of the Qinghai-Tibet plateau. Metallic deposits, including lead-zinc deposits, are widespread in the region. In the following analysis, DOM from Lake Qardam, 
Da Qaidam Salt Lake and West Ginair are referred to as LQDOM, DQDOM and WGDOM, respectively

Samples were collected from the seepage of brine from pools which were dug with pre-treated equipment. Two $2.5 \mathrm{~L}$ bottles were sealed in sterile (acid-rinsed) plastic buckets. The collected samples were filtered immediately (on site) through $0.7 \mu \mathrm{m}$ pore size glass fiber filters (Whatman GF/F, combusted at 450 for 5 $\mathrm{h}$ before use), and kept on ice and in the dark during transported to the laboratory.

\section{DOM fractionation}

The procedure for DOM isolation by means of SPE has been described previously (K. Yang, Zhang, Dong, \& Li, 2017; K. Yang, Zhang, Dong, Nie, \& Li, 2017). Briefly, each $200 \mathrm{~mL}$ acidified filtrate was loaded on the preconditioned PPL cartridge, and then isolated under reduced pressure. Two cartridge volumes Milli-Q water were used to remove salts, and methanol:water(v/v:9:1) was used to eluted the DOM. The elution was dried in a vacuum oven (removing methanol) and diluted to initial volume with Milli-Q water for spectroscopic and DOC analysis.

The filtered brine samples were further fractionated into LMW ( $<1 \mathrm{kDa})$ and HMW $(1 \mathrm{kDa}-0.7 \mu \mathrm{m})$ DOM using UF. Briefly, aliquots of each sample $(200 \mathrm{~mL})$ was loaded on a $1 \mathrm{kDa}$ pre-cleaned membrane disc operated on the stirred cell ultrafiltration system (Amicon, USA), with a $\mathrm{N}_{2}$ pressure of $345 \mathrm{kPa}$ and concentration factor of 40 (Guo, Wen, Tang, \& Santschi, 2000). The permeate solution is LWM DOM and the retentates are HMW DOM. Salts were further removed from the retentate via diafiltration with Milli-Q water). HMW fractions were further diluted to the $200 \mathrm{~mL}$ volume for spectroscopic and DOC analysis.

\section{DOC analysis}

The concentrations of DOC for the bulk and fractionated DOM samples were measured using a high temperature catalytic oxidation method performed on a total organic carbon analyzer (Analytik Jena N/C 3100, Germany). Due to high salinity, it was necessary to dilute the samples (1:10) with MilliQ-water before analysis. Moreover, all samples (including following sections) were measured in duplicate. one-way ANOVA tests were conducted to examine the significance of differences in data between different sample sets.

\section{Measurements of optical properties}

The UV-Vis absorption data were obtained at the wavelength range from 190 to $800 \mathrm{~nm}$ at $1 \mathrm{~nm}$ increments using a spectrophotometer (TU-1901, Puxi). Parameters such as absorption coefficient $(\mathrm{a}(\lambda)=2.303 \mathrm{~A}(\lambda) /$ L), spectral slope for the interval of $275295 \mathrm{~nm}\left(S_{275} 295\right)$ as well as specific UV absorbance at $254 \mathrm{~nm}$ $\left(\mathrm{SUVA}_{254}\right)$ were calculated as absorption coefficient a $(\lambda)$ normalized to DOC concentration.

Fluorescence excitation-emission matrix (EEM) spectra were obtained using a Hitachi F-7000 spectrofluorometer with an excitation (Ex) range set from 200 to $500 \mathrm{~nm}$ in $10 \mathrm{~nm}$ increments and an emission (Em) range set from 250 to $550 \mathrm{~nm}$ in $2 \mathrm{~nm}$ increments. Instrument parameters were excitation and emission slits, $5 \mathrm{~nm}$; response time, auto; scan speed, $2400 \mathrm{~nm} \mathrm{~min}^{-1}$, and several preprocessing steps were used to minimize interference scatter lines and inner-filtering effects accordingly(Murphy, Stedmon, Graeber, \& Bro, 2013; Ohno, Amirbahman, \& Bro, 2007; Stedmon \& Bro, 2008).

On the basis of EEM data, some fluorescence indices, i.e., fluorescence index (FIX, the ratio of fluorescence intensities between Em $450500 \mathrm{~nm}$ at Ex $370 \mathrm{~nm}$ ), biological index (BIX, the ratio of Em intensity at 380 $\mathrm{nm}$ divided by the Em intensity maximum in $420435 \mathrm{~nm}$, obtained at Ex $310 \mathrm{~nm}$ ), and humification index (HIX, the area under the Em435-480 nm divided by the peak area under the Em $300345+435480 \mathrm{~nm}$, at Ex $254 \mathrm{~nm}$ ) were obtained herein(DeVilbiss, Zhou, Klump, \& Guo, 2016; McKnight et al., 2001).

\section{Determination of total carbohydrate}

The determination of carbohydrate concentration was based on a spectrophotometric method described earlier (Hung, Tang, Warnken, \& Santschi, 2001; Myklestad, Skånøy, \& Hestmann, 1997). Briefly, an aliquot of sample was placed into a $5 \mathrm{~mL}$ ampoule, to which $1 \mathrm{~N} \mathrm{HCl}$ was added for hydrolysis. The ampoule was flame-sealed and held at $100{ }^{\circ} \mathrm{C}$ for $24 \mathrm{~h}$, followed by addition of $1 \mathrm{M} \mathrm{NaOH}$. The neutralized solution was 
mixed with a $0.7 \mathrm{M}$ potassium ferricyanide and held at $100{ }^{\circ} \mathrm{C}$ for $10 \mathrm{~min}$, following addition of $1 \mathrm{~mL}$ of $2 \mathrm{M}$ ferric chloride solution and $2 \mathrm{~mL}$ of $2.5 \mathrm{M} \mathrm{2,4,6-tripyridyl-s-triazine} \mathrm{(TPTZ),} \mathrm{and} \mathrm{mixed} \mathrm{on} \mathrm{a} \mathrm{Vortex.}$ After standing for $30 \mathrm{~min}$, the absorbance was measured at a wavelength of $595 \mathrm{~nm}$. The concentration of total carbohydrates (TCHO) was measured using an external standard method (standard curve of glucose solutions). The concentration of TCHO is expressed as mg-c/L.

\section{PARAFAC analysis}

PARAFAC modeling of EEMs has been described in detail elsewhere (Andersen \& Bro, 2003; Stedmon, Markager, \& Bro, 2003). In this study, the PARAFAC modeling was conducted in MATLAB 9.5.0 (Mathworks, Natick, MA). After several post-acquisition steps for the original EEM spectra, the PARAFAC model provides an estimate of the number of fluorophores as well as the excitation and emission spectrum of these fluorophores.

\section{Fluorescence titration and complexation modeling}

The complexing properties of bulk and MW-fractionated DOM samples for $\mathrm{Pb}(\mathrm{II})$ were determined by the titration experiment(Ohno et al., 2007; Jun Wu et al., 2012; H. Xu, Yan, Li, Jiang, \& Guo, 2018). Briefly, the samples were stepwise diluted to $[\mathrm{DOC}]<10 \mathrm{mg} / \mathrm{L}$ using Milli-Q water to minimize inner filtering effects(Ohno, 2002). Then, aliquots of $20 \mathrm{~mL}$ diluted solution were titrated with a $\mathrm{Pb}$ (II) using an automatic syringe in $60 \mathrm{~mL}$ sealed vials. The concentrations of $\mathrm{Pb}(\mathrm{II})$ in the final solutions ranged from 0 to $1000 \mu \mathrm{M}$ via addition of $<20 \mu \mathrm{L}$ of titrant. The $\mathrm{pH}$ values of the titrated solutions were maintained at 6.0 to ensure that no precipitate formed in the process. To ensure complexation equilibrium, all titrated solutions were shaken in an incubator in the dark for $24 \mathrm{~h}$ at 25 . The modified Stern-Volmer model was used to determine the binding parameters for $\mathrm{Pb}(\mathrm{II})$ with the PARAFAC-derived components(Hays, Ryan, \& Pennell, 2004).

\section{Results and Discussion}

\section{Abundances and performance comparison in different isolation approaches based on DOC analysis andcarbohydrates}

DOC analysis (Table 1) showed that the bulk DOM solutions contained 41.70, 19.89 and $28.74 \mathrm{mg} / \mathrm{L}$, for LQDOM, DQDOM and WGDOM, respectively. These values are higher than estimates of the world average of DOC in surface waters $(6.48 \mathrm{mg} / \mathrm{L})$ or open ocean surface waters $(0.7441 .44 \mathrm{mg} / \mathrm{L})($ Dittmar et al., 2008; E. Minor \& Stephens, 2008; Retelletti Brogi et al., 2018), and are in the same range as DOC content of the Great Salt Lake ( $40 \mathrm{mg} / \mathrm{L}$ )(Leenheer, Noyes, Rostad, \& Davisson, 2004), but these values were lower than the DOC value reported in brines from Lake Vida (> $580 \mathrm{mg} / \mathrm{L}$ ), in the McMurdo Dry Valleys(Cawley et al., 2016). These results indicated that many brine waters or hypersaline lakes have higher DOC concentrations than other aquatic systems.

For the SPE-DOM, the DOC concentration was 13.89, 7.21 and $10.86 \mathrm{mg} / \mathrm{L}$ for LQDOM, DQDOM and WGDOM respectively, while DOC was 11.68, 5.15 and $9.1 \mathrm{mg} / \mathrm{L}$ for UF-DOM (HMW). Hence, SPE-DOM accounted for $33.31 \%, 36.25 \%$ and $37.79 \%$ of DOC in the bulk solutions for the three sites, whereas UF-DOM accounted for $28.01 \%, 29.56 \%$, and $31.66 \%$, respectively. The results indicated that SPE exhibited higher DOC recovery than UF for the hypersaline water DOM isolation. These values were significantly lower than previously reported values for the use of SPE on the freshwater (river or lake) and seawater samples worldwide(Dittmar et al., 2008; Y. Li et al., 2016; Y. Li et al., 2017), indicating that the presence of excess inorganic ions in the brines may negatively affect DOM isolation efficiency for SPE and UF. Regarding the MW fractions, a large portion of total DOC abundance was located in the LMW fraction (about $2 / 3$ of the DOM; Table 1). The HMW fraction in brine water DOM was generally lower than that in sediment DOM $(50 \%)$ and river water $(40.3 \%)$, but comparable with lake water $(30.2 \pm 0.4 \%)$, seawater $(23.2 \pm 1.1 \%)$, and estuary $(33 \pm 6 \%)(\mathrm{H} . \mathrm{Xu} \&$ Guo, 2017; H. Xu et al., 2019). The relatively low concentration of HMW-DOM in the hypersaline waters, or at least of the DOM that is recovered using UF, may be related to the minor terrestrial DOM component in these systems(Helms et al., 2008).

\section{Spectral properties of chromophoric and fluorescent DOM}




\section{UV-Vis spectra analysis}

Spectral paraments for UV-Vis are shown in Table 1. The SUVA 254 data of bulk DOM were 1.53 \pm 0.11 , $1.67 \pm 0.15$ and $2.09 \pm 0.09$ for LQDOM, DQDOM and WGDOM, respectively. Our SUVA 254 values were significantly lower than that in the other natural waters(Helms et al., 2008; H. Xu \& Guo, 2017), indicating that the salt lake brine water DOM herein contain a relatively low proportion of aromatic groups, perhaps due to the absence of terrestrial organic material inputs such as lignin or humic acids(H. Li \& Minor, 2015).

As for the fractions based on different isolation approaches, the $\mathrm{SUVA}_{254}$ value of SPE-DOM were higher than that of UF-DOM, indicating that SPE tended to retain aromatics or hydrophobic materials, which is consistent with previous studies(Y. Li et al., 2017; Perminova et al., 2014). For the MW size fractions, the HMW had higher $\mathrm{SUVA}_{254}$ than the LMW, for LQDOM and DQDOM, while the reverse results were observed for WGDOM samples. The results indicated that HMW-DOM were characterized with higher aromaticity than the LMW counterparts for LQDOM and DQDOM. Thus, the spectral properties were different between the isolation approaches, as well as the MW fractions and DOM sampling locations.

The $S_{275-295}$ is inversely related to the MW of the DOM. No systematic trend was found for $S_{275-295}$ values between SPE-DOM and UF-HMW fractions in all samples. The results enhanced the conclusion that the mechanism of SPE retained DOM depending on hydrophilic-lipophilic interactions rather than MW $(\mathrm{H}$. Li \& Minor, 2015). Moreover, the higher $S_{275-295}$ values (Table 1) in LMW fraction for the samples in this study confirmed an overall small molecular size for LMW-DOM and the efficiency of ultrafiltration procedure applied in this study for MW fractionation.

\section{Fluorescence EEM spectra of bulk DOMs and isolated fractions}

Fig. 1 shows the EEM contours of bulk DOM samples and isolated fractions with different isolation procedures. Although multiple peaks overlapped in the EEM contours, the bulk DOM was characterized by three similar main peaks, i.e., peak A (Ex/Em: 320/400 nm), peak B (Ex/Em: 260/400 nm) and peak C (Ex/Em: 260/410 nm). Peak A was ascribed as UVC humic-like, whereas peaks B and C can be assigned as UVA humic-like(Coble, 1996; Leenheer \& Croué, 2003; Stedmon et al., 2003). Interestingly, the fluorophores were all ascribed to humic-like substances, and the protein-like (tryptophan or tyrosine) fractions(Coble, Green, Blough, \& Gagosian, 1990; Ohno et al., 2007), were not detectable. The may be explained by the low microbial activity in hypersaline brines(Waiser \& Robarts, 2000). Comparison of the EEM contours (Fig. 1) between bulk DOM and their isolated fractions, showed that SPE isolates DOM that is markedly different from bulk DOM, probably due to selective retention, $\mathrm{pH}$ changes or solvent usages leading to irreversible chemical alterations of the resulting isolates. To the contrary, both HMW and LMW fractions isolated by UF shared similar fluorophores as bulk DOM.

Despite the similar EEM contours between bulk DOM and UF-DOM, some differences are apparent from the fluorescence intensities, such as that of peak A, which was higher than peak B and C (the two peaks very closed) in bulk and LMW DOM (except for DQDOM), while the opposite was observed for the HMW-DOM, irrespective of the sample origin. The fluorescence intensity of peak A was lower than that of peaks B and $\mathrm{C}$ for the DQDOM regardless of the MW, indicating that even the same component extracted from various origin may also possess various spectral properties.

\section{MW-dependent fluorescence indices of salt lake brine DOMs from different sources}

The FIX (Table 1) served as a simple index to distinguish sources with higher values ( 1.9$)$ indicating microbial DOM and lower values ( $\sim 1.4)$ related to terrestrial DOM sources. In our study, the FIX of all samples ranged from 2.05 to 2.68, significantly higher than that in other reported aquatic samples, such as river samples (1.4 1.5), groundwater samples (1.9), lakes (1.3 1.9) and Green Bay estuary (1.1 1.3)(DeVilbiss et al., 2016; McKnight et al., 2001), and also higher than sediment-derived DOM (1.3 1.6)(Huacheng Xu, Guo, \& Jiang, 2016). For the bulk and MW fractionated samples, the HMW-DOM had consistently lower FIX (2.05 2.09) than the LMW-DOM (2.37 2.68), indicating that microbial source moieties were mainly distributed in the LMW fraction. The BIX, which indicates the contribution of autochthonous or freshly 
produced DOM, was significantly higher in LMW-DOM irrespective of the sample types, indicating in situ produced DOM mainly in LMW-DOM. The HIX, an indicator of the degree of DOM humification(Ohno, 2002), was no significant systemic tend for the bulk and MW-fractionated samples, indicating a comparable humification degree.

\section{Distribution of carbohydrates in different fractions based on isolation approach}

The concentration of TCHO for SPE-DOM and UF-HMW (Table 1) ranged from $1.68 \mathrm{mg}$ C/L in the Da Qaidam Salt Lake to $2.13 \mathrm{mg}$ C/L in the Lake Qardam for UF-HMW DOM, and these values are higher than those previously reported in both freshwater (river and lake waters) and seawater(H. Xu \& Guo, 2017). In terms of UF-HMW DOC, the percentages of TCHO varied from $18.24 \%$ to $28.54 \%$, which were lower than those reported previously in both Jourdan River and Gulf of Mexico (55\%-72\%). The results agreed well with previous observations that the percentage of HMW TCHO generally decreased with increasing salinity(Xuri Wang, Cai, \& Guo, 2010).

Compared with UF-HMW DOMs, TCHO had a relatively low percentage in the SPE-DOM, ranging from $13.40 \%$ to $14.42 \%$, and suggests that UF retains more carbohydrates than SPE. This is consistent with previous results obtained by ${ }^{13} \mathrm{C}$ NMR analysis of marine DOM(Koprivnjak et al., 2009). Thus, caution is demanded when different isolation approaches are compared.

\section{PARAFAC analysis}

\section{Fluorescent components derived from PARAFAC modeling}

PARAFAC models with three components were successfully identified for the bulk and MW fractions based on the results of the residual and split half analysis. As depicted in Fig. 2, component 1 (C1) exhibited two peaks with Ex/Em of 250/400 and 310/400 nm, ascribed to humic-like component(X. Yang, Meng, \& Meng, 2019). Component $2(\mathrm{C} 2, \mathrm{Ex} / \mathrm{Em}=260 / 480 \mathrm{~nm})$ was identified as fulvic acid substance(Leenheer \& Croue, 2003; X. Yang et al., 2019). Component 3 ( C3) had a peak at Ex/Em $=280 / 480 \mathrm{~nm}$ and can be defined as humic acid-like organics(W. Chen, Westerhoff, P., Leenheer, J. A., \& Booksh, K, 2003). Compared to the peaks derived from EEM contours (section 3.2), the PARAFAC-derived components showed a redshifting of the peak from Ex260/Em400 to Ex280/Em480. This red-shifting may relate to metal addition after acidification, as reported for iron-DOM complexes (Cawley et al., 2016; Weber, Allard, \& Benedetti, 2006). Overall, the PARAFAC-derived components were all identified as humic substance, demonstrating the absence of protein-like materials in the brine, corresponding with the results of EEM contours analysis. This suggests that the microbial-derived DOM, which may be expected to be rich in protein or other N-containing macromolecules, had been subjected to considerable degradation.

The quantitative distribution of PARAFAC-derived components and isolated fractions in the brine DOM (Fig. 3) show similar proportions of the MW fractions (Fig. 3a). Moreover, the humic-like C1 (Fig. 3b) had the highest relative abundance in all samples, followed by $\mathrm{C} 2$ and $\mathrm{C} 3$, irrespective of the sample types.

\section{Behavior ofPARAFAC-derived components binding with $\mathrm{Pb}(\mathrm{II})$}

The variations in fluorescent intensity scores of the PARAFAC-derived components during metal $(\mathrm{Pb}) \mathrm{ad}-$ dition are illustrated in Fig. 4. Entirely different quenching effects were observed for $\mathrm{Pb}$ (II) by the three components. When metal addition was applied, $\mathrm{C} 1$ exhibited an initially decrease followed by a gradual decline or stabilization regardless of the sample types, and the trends of quenching curves were generally in accordance with the previous studies for humic-like fractions derived from various sources using fluorescence quenching titration with different trace metals(Ohno et al., 2007; J. Wu, Zhang, He, \& Shao, 2011; Yamashita \& Jaffe, 2008). The decline of fluorescent intensities suggested an effective binding of $\mathrm{C} 1$ with metals(Ohno et al., 2007; Stedmon et al., 2003), and suggests that C1 played a key role in the complexation between heavy metals and DOM in brine waters.

All C2 fluorescent components (except the C2 of HMW-DOM) increased sharply at low metal concentrations (e.g., $<200 \mu \mathrm{M}$ ), followed by a rapid decline upon further additions, indicating different binding mechanisms 
between the $\mathrm{C} 1$ and $\mathrm{C} 2$ fluorophores. The increases in fluorescence intensity at the initial stages of the titration may reflect the quenching of the fluorescence of $\mathrm{C} 2$ due to interactions with inorganic components in the initial brine. The fluorescence intensity could be enhanced due to competition between inorganics and $\mathrm{Pb}$ (II) resulting in the release of $\mathrm{C} 2$ components from the DOM-inorganic complexes. With the addition of $\mathrm{Pb}(\mathrm{II})$, the fluorescence of $\mathrm{C} 2$ component may be quenched due to the replacement of the original quencher in the DOM-inorganic complexes through the competition with $\mathrm{Pb}(\mathrm{II})$ whereby more stable $\mathrm{DOM}-\mathrm{Pb}(\mathrm{II})$ complexes are formed at later stages. The fluorescence titrating curves of $\mathrm{C} 2$ with $\mathrm{Pb}$ (II) for HMW DOM were different from the bulk- and LMW-DOM irrespective of sample origin, namely a sharp increase at low metal concentrations (e.g., $<200 \mu \mathrm{M}$ ) followed by a gradual stabilization for further addition. This differences in fluorescent intensity at the later stage can be ascribed to the changes in the molecular environments of HMW DOM caused by increasing metal concentrations(Yamashita \& Jaffe, 2008).

Compared with fluorescent quenching of $\mathrm{C} 1$, the reverse trend was observed for $\mathrm{C} 3$, which was also reported in previous studies(Ohno et al., 2007; J. Wu et al., 2011), and confirmed the different binding mechanisms for the three components. Based on pioneering papers on the use of fluorescence spectrometry to determine the behavior of metal-ligand, this phenomenon can be ascribed to multiple factors (Yamashita \& Jaffe, 2008), including changes in quantum yields of fluorophores and the replacement of the other quencher or C3 during $\mathrm{Pb}$ (II) addition.

\section{MW-dependent binding properties of PARAFAC-derived components}

Further analysis showed that the quenching extents of fluorescent components exhibited clear differences related to sampling location and $\mathrm{MW}$. With the addition of $\mathrm{Pb}(\mathrm{II})$, the intensities of fluorescent $\mathrm{C} 1$ in bulk LQDOM decreased by $36.7 \%$ (from 53.9 to $34.1 \mathrm{~A} \cdot \mathrm{U} / \mathrm{mg}-\mathrm{C} / \mathrm{L}$ ), which was lower than the decline observed for bulk DQDOM and WGDOM (44.0\% and $43.3 \%$, from 116.5 and 92.8 to 65.2 and $52.7 \mathrm{~A} \cdot \mathrm{U} / \mathrm{mg}-\mathrm{C} / \mathrm{L}$, respectively). The results indicated that the humic-like component in DQDOM had higher binding potential than the same component in the LQDOM and WGDOM samples, which may be attributed to the higher humification degree of the former (level of decay reflected by HIX). As for the MW fractions, the quenching degrees of $\mathrm{C} 1$ in HMW fraction were generally higher than those in LMW fraction for LQDOM and DQDOM (47.4-56.6 vs. 42.7-42.8\%), while the inverse was true for fractions of WGDOM.

The stability constants $\left(\log K_{\mathrm{M}}\right)$ and $f$ values based on the modified Stern-Volmer model were calculated (Table 2) to reveal the MW-dependent metal binding behaviors of humic-like fluorescent component (C1). The $\log K_{\mathrm{M}}$ values ranged from 1.81 to 2.38 , which were significantly lower than those reported for commercial humic acids (4.28 5.15) (H. Xu et al., 2018) as well as those found for the binding of other metals (i.e., $\mathrm{Cu}(\mathrm{II}), \mathrm{Fe}(\mathrm{III}), \mathrm{Al}(\mathrm{III})$ and $\mathrm{Hg}(\mathrm{II})$ ) from various sources(Hur \& Lee, 2011; Ohno et al., 2007; J. Wu et al., 2011; Yamashita \& Jaffe, 2008; Yu et al., 2012). This discrepancy may be partly due to the abundance of inorganic ion in the brine, which can compete with lead complexation. Further analysis showed that the Log $K_{\mathrm{M}}$ values of $\mathrm{C} 1$ for bulk LQDOM were slightly lower than for the bulk DQDOM and WGDOM samples. This indicated that humic-like components in DQDOM and WGDOM had a stronger binding affinity than LQDOM. As for the MW fractions, the $\log K$ M values of $\mathrm{C} 1$ in HMW fraction were higher than those in LMW fraction for the LQDOM and DQDOM samples (Table 2). In summary, the HMW-DOM exhibited higher binding affinities with $\mathrm{Pb}$ (II) than LOW-DOM, which was in agreement with their quenching extents.

The $f$ values of the fluorescent components in bulk DOM and MWs samples ranged from 0.30 to 0.63 , which were in the same ranges as compared to other natural DOM(W. B. Chen, Smith, \& Gueguen, 2013; H. Xu et al., 2018). Certainly, the difference of the bulk- and MW-fractions were also observed for $f$ values. For instance, the $f$ values of $\mathrm{C} 1$ in the LMW fraction exceeded those in the HMW for LQDOM and WGDOM, while the obviously reverse trend was observed for DQDOM fractions.

\section{Implication for the utilization of salt lake brine resource}

The results may have important implications for the evaluation of DOM treatment and their ecological impacts and consequences. For example, spectral titration experiments showed that, among these PARAFAC derived-components, C2 and C3 may be the preferential organic constitutes binding with minerals, and then 
affected the quality of products (color and grade). The modified Stern-Volmer model further showed the stability constants $\log K_{\mathrm{M}}$ and binding capacities $(f)$ of organic ligand $(\mathrm{C} 1)$ with trace metal, indicating $\mathrm{C} 1$ could be capable of migrating and transporting trace metals by formation of organometallic complexes in the Qaidam Basin plateau region, although it exhibited a relatively lower metal binding potential than that in the other natural waters, probably due to competition with salts. Certainly, further research is needed to characterize the DOM at the molecular scale, including non-fluorescent compositional features such as abundances of lignin and other polyphenolic DOM derivatives, as well as their behaviors in the biogeochemical cycling of trace metals and the mobility of colloidal particles of minerals in salt lake environments.

\section{Conclusions}

This study showed that salt lake brine DOM generally contains higher DOC and FIX, but lower SUVA 254 than that for other natural waters, and the humic-like substances were the only observed fluorophores. Isolation of DOM by SPE recovered a larger proportion of the DOM, probably more aromatics (and less carbohydrates), than UF. Moreover, SPE may induce compositional changes of bulk DOM. $\mathrm{Pb}(\mathrm{II})$ titration experiment showed that PARAFAC-derived components exhibited different quenching behavior. Further analysis indicated that PARAFAC-derived $\mathrm{C} 1$ component exhibited higher $\mathrm{Pb}(\mathrm{II})$ binding affinities for bulk DQDOM than for LQDOM and WGDOM. The HMW-DOM was had higher $\mathrm{Pb}(\mathrm{II})$ binding potential than the LMW counterparts for LQDOM, while the reverse results was true for DQDOM and WGDOM. This paper extended our knowledge on the composition and properties of DOM in salt lake brine environment.

\section{Acknowledgments}

We gratefully thank Natural Science Foundation of Qinghai Province (2020-ZJ-940Q), West Light Foundation of the Chinese Academy of Sciences (E010GC09) for their financial support on this study. Moreover, We thank Kaal Joeri for his valuable comments on an earlier version of the manuscript.

\section{Conflict of interest statement}

The authors have no conflict of interest to declare.

\section{Data availability statement}

The data that support the findings of this study are available from the corresponding author upon reasonable request.

\section{References}

Abdulla, H. A. N., Minor, E. C., Dias, R. F., \& Hatcher, P. G. (2010). Changes in the compound classes of dissolved organic matter along an estuarine transect: A study using FTIR and 13C NMR. Geochimica et Cosmochimica Acta, 74 (13), 3815-3838. doi:10.1016/j.gca.2010.04.006

Andersen, C. M., \& Bro, R. (2003). Practical aspects of PARAFAC modeling of fluorescence excitationemission data. Journal of Chemometrics: A Journal of the Chemometrics Society, 17 (4), 200-215.

Carstea, E. M., Baker, A., Pavelescu, G., \& Boomer, I. (2009). Continuous fluorescence assessment of organic matter variability on the Bournbrook River, Birmingham, UK. Hydrological Processes, 23 (13), 1937-1946. doi:10.1002/hyp.7335

Cawley, K. M., Murray, A. E., Doran, P. T., Kenig, F., Stubbins, A., Chen, H., . . . McKnight, D. M. (2016). Characterization of dissolved organic material in the interstitial brine of Lake Vida, Antarctica. Geochimica et Cosmochimica Acta, 183 , 63-78. doi:10.1016/j.gca.2016.03.023

Chen, W., Smith, D., \& Guéguen, C. (2013). Influence of water chemistry and dissolved organic matter (DOM) molecular size on copper and mercury binding determined by multiresponse fluorescence quenching. Chemosphere, 92 (4), 351-359.

Chen, W., Westerhoff, P., Leenheer, J. A., \& Booksh, K. (2003). Fluorescence excitation- emission matrix regional integration to quantify spectra for dissolved organic matter. Environmental Science 85 Technology, 
$37(24), 5701-5710$.

Chen, W. B., Smith, D. S., \& Gueguen, C. (2013). Influence of water chemistry and dissolved organic matter (DOM) molecular size on copper and mercury binding determined by multiresponse fluorescence quenching. Chemosphere, 92 (4), 351-359. doi:10.1016/j.chemosphere.2012.12.075

Christl, I., Milne, C. J., Kinniburgh, D. G., \& Kretzschmar, R. (2001). Relating ion binding by fulvic and humic acids to chemical composition and molecular size. 2. Metal binding. Environmental Science $\mathcal{G}$ Technology, 35 (12), 2512-2517. doi:10.1021/es0002520

Coble, P. G. (1996). Characterization of marine and terrestrial DOM in seawater using excitation-emission matrix spectroscopy. Marine Chemistry, 51 (4), 325-346.

Coble, P. G., Green, S. A., Blough, N. V., \& Gagosian, R. B. (1990). Characterization of dissolved organic matter in the Black Sea by fluorescence spectroscopy. Nature, 348 (6300), 432-435.

de Zarruk, K. K., Scholer, G., \& Dudal, Y. (2007). Fluorescence fingerprints and Cu2+-complexing ability of individual molecular size fractions in soil-and waste-borne DOM. Chemosphere, 69 (4), 540-548.

DeVilbiss, S. E., Zhou, Z., Klump, J. V., \& Guo, L. (2016). Spatiotemporal variations in the abundance and composition of bulk and chromophoric dissolved organic matter in seasonally hypoxia-influenced Green Bay, Lake Michigan, USA. Science of the Total Environment, 565 , 742-757.

Dittmar, T., Koch, B., Hertkorn, N., \& Kattner, G. (2008). A simple and efficient method for the solid-phase extraction of dissolved organic matter (SPE-DOM) from seawater. Limnology and Oceanography: Methods, $6(6), 230-235$.

Fan, C. H., Chang, M., \& Zhang, Y. C. (2016). Spectral Characteristics of Dissolved Organic Matter (DOM) Derived from Water and Sediment in Normal Flow Period of the Intersection Zone of Jing River and Wei River.Spectroscopy and Spectral Analysis, 36 (9), 2863-2869. doi:10.3964/j.issn.1000-0593(2016)09-2863-07

Fan, X., Song, J., \& Peng, P. (2013). Comparative study for separation of atmospheric humic-like substance (HULIS) by ENVI-18, HLB, XAD-8 and DEAE sorbents: elemental composition, FT-IR, 1H NMR and off-line thermochemolysis with tetramethylammonium hydroxide (TMAH). Chemosphere, 93 (9), 1710-1719. doi:10.1016/j.chemosphere.2013.05.045

Fan, X., Song, J., \& Peng, P. a. (2012). Comparison of isolation and quantification methods to measure humic-like substances (HULIS) in atmospheric particles. Atmospheric Environment, 60 , 366-374. doi:10.1016/j.atmosenv.2012.06.063

Gueguen, C., \& Cuss, C. W. (2011). Characterization of aquatic dissolved organic matter by asymmetrical flow field-flow fractionation coupled to UV-Visible diode array and excitation emission matrix fluorescence. Journal of Chromatography A, 1218 (27), 4188-4198. doi:10.1016/j.chroma.2010.12.038

Guo, L., Wen, L.-S., Tang, D., \& Santschi, P. H. (2000). Re-examination of cross-flow ultrafiltration for sampling aquatic colloids: evidence from molecular probes. Marine Chemistry, 69 (1-2), 75-90.

Hays, M. D., Ryan, D. K., \& Pennell, S. (2004). A modified multisite stern-volmer equation for the determination of conditional stability constants and ligand concentrations of soil fulvic acid with metal ions. Analytical Chemistry, 76 (3), 848-854. doi:10.1021/ac0344135

Helms, J. R., Stubbins, A., Ritchie, J. D., Minor, E. C., Kieber, D. J., \& Mopper, K. (2008). Absorption spectral slopes and slope ratios as indicators of molecular weight, source, and photobleaching of chromophoric dissolved organic matter. Limnology and Oceanography, 53 (3), 955-969.

Hosen, J. D., Armstrong, A. W., \& Palmer, M. A. (2018). Dissolved organic matter variations in coastal plain wetland watersheds: The integrated role of hydrological connectivity, land use, and seasonality. Hydrological Processes, 32 (11), 1664-1681. doi:10.1002/hyp.11519 
Hung, C.-C., Tang, D., Warnken, K. W., \& Santschi, P. H. (2001). Distributions of carbohydrates, including uronic acids, in estuarine waters of Galveston Bay. Marine Chemistry, 73 (3-4), 305-318.

Hur, J., \& Lee, B. M. (2011). Characterization of binding site heterogeneity for copper within dissolved organic matter fractions using two-dimensional correlation fluorescence spectroscopy. Chemosphere, 83 (11), 1603-1611. doi:10.1016/j.chemosphere.2011.01.004

Hussain A. N. Abdulla, Elizabeth C. Minor, and Patrick G. Hatcher ,. (2010). Using Two-Dimensional Correlations of 13C NMR and FTIR To Investigate Changes in the Chemical Composition of Dissolved Organic Matter along an Estuarine Transect. Environmental Science and Technology, 44, 8044-8049.

Koprivnjak, J. F., Pfromm, P. H., Ingall, E., Vetter, T. A., Schmitt-Kopplin, P., Hertkorn, N., . . . Perdue, E. M. (2009). Chemical and spectroscopic characterization of marine dissolved organic matter isolated using coupled reverse osmosis-electrodialysis. Geochimica et Cosmochimica Acta, 73 (14), 4215-4231. doi:10.1016/j.gca.2009.04.010

Kruger, B. R., Dalzell, B. J., \& Minor, E. C. (2011). Effect of organic matter source and salinity on dissolved organic matter isolation via ultrafiltration and solid phase extraction. Aquatic Sciences, 73 (3), 405-417. doi:10.1007/s00027-011-0189-4

Lakshman, S., Mills, R., Patterson, H., \& Cronan, C. (1993). Apparent differences in binding-site distributions and aluminum(iii) complexation for 3 molecular-weight fractions of a coniferous soil fulvicacid.Analytica Chimica Acta, 282 (1), 101-108. doi:10.1016/0003-2670(93)80357-q

Leenheer, J. A., \& Croue, J.-P. (2003). Peer reviewed: characterizing aquatic dissolved organic matter. Environmental Science $\&$ Technology .

Leenheer, J. A., Noyes, T. I., Rostad, C. E., \& Davisson, M. L. (2004). Characterization and origin of polar dissolved organic matter from the Great Salt Lake. Biogeochemistry, 69 (1), 125-141.

Li, H., \& Minor, E. C. (2015). Dissolved organic matter in Lake Superior: insights into the effects of extraction methods on chemical composition. Environmental Science Processes $\mathscr{G}$ Impacts, 17 (10), 18291840. doi:10.1039/c5em00199d

Li, Y., Harir, M., Lucio, M., Kanawati, B., Smirnov, K., Flerus, R., . . . Hertkorn, N. (2016). Proposed Guidelines for Solid Phase Extraction of Suwannee River Dissolved Organic Matter. Analytical Chemistry, 88 (13), 6680-6688. doi:10.1021/acs.analchem.5b04501

Li, Y., Harir, M., Uhl, J., Kanawati, B., Lucio, M., Smirnov, K. S., . . . Hertkorn, N. (2017). How representative are dissolved organic matter (DOM) extracts? A comprehensive study of sorbent selectivity for DOM isolation. Water Research, 116 , 316-323. doi:10.1016/j.watres.2017.03.038

Li, Z., Peng, H., Xie, B., Liu, C., Nie, X., Wang, D., . . . Jiang, J. (2020). Dissolved organic matter in surface runoff in the Loess Plateau of China: The role of rainfall events and land-use. Hydrological Processes, 34 (6), 1446-1459. doi:10.1002/hyp.13660

McKnight, D. M., Boyer, E. W., Westerhoff, P. K., Doran, P. T., Kulbe, T., \& Andersen, D. T. (2001). Spectrofluorometric characterization of dissolved organic matter for indication of precursor organic material and aromaticity. Limnology and Oceanography, 46 (1), 38-48.

Minor, E., \& Stephens, B. (2008). Dissolved organic matter characteristics within the Lake Superior watershed. Organic Geochemistry, 39 (11), 1489-1501. doi:10.1016/j.orggeochem.2008.08.001

Minor, E. C., Swenson, M. M., Mattson, B. M., \& Oyler, A. R. (2014). Structural characterization of dissolved organic matter: a review of current techniques for isolation and analysis. Environ Sci Process Impacts, 16 (9), 2064-2079. doi:10.1039/c4em00062e

Murphy, K. R., Stedmon, C. A., Graeber, D., \& Bro, R. (2013). Fluorescence spectroscopy and multi-way techniques. PARAFAC.Analytical Methods, 5 (23). doi:10.1039/c3ay41160e 
Myklestad, S. M., Skanoy, E., \& Hestmann, S. (1997). A sensitive and rapid method for analysis of dissolved mono-and polysaccharides in seawater. Marine Chemistry, 56 (3-4), 279-286.

Ohno, T. (2002). Fluorescence inner-filtering correction for determining the humification index of dissolved organic matter. Environmental Science 83 Technology, 36 (4), 742-746.

Ohno, T., Amirbahman, A., \& Bro, R. (2007). Parallel factor analysis of excitation-emission matrix fluorescence spectra of water soluble soil organic matter as basis for the determination of conditional metal binding parameters. Environmental Science \&3 Technology, 42 (1), 186-192.

Peng-Sheng, S., Wu, L., Bai, S., Zhen, N., Ling-Zhong, B., \& Yun-Sheng, W. (2011). Recent Development on Comprehensive Utilization of Salt Lake Resources. Chinese Journal of Inorganic Chemistry, 27 (5), 15.

Perminova, I. V., Dubinenkov, I. V., Kononikhin, A. S., Konstantinov, A. I., Zherebker, A. Y., Andzhushev, M. A., . . . Nikolaev, E. N. (2014). Molecular mapping of sorbent selectivities with respect to isolation of Arctic dissolved organic matter as measured by Fourier transform mass spectrometry. Environmental Science and Technology, 48 (13), 7461-7468. doi:10.1021/es5015423

Retelletti Brogi, S., Ha, S. Y., Kim, K., Derrien, M., Lee, Y. K., \& Hur, J. (2018). Optical and molecular characterization of dissolved organic matter (DOM) in the Arctic ice core and the underlying seawater (Cambridge Bay, Canada): Implication for increased autochthonous DOM during ice melting. Science of the Total Environment, 627, 802-811. doi:10.1016/j.scitotenv.2018.01.251

Sandron, S., Rojas, A., Wilson, R., Davies, N. W., Haddad, P. R., Shellie, R. A., . . . Paull, B. (2015). Chromatographic methods for the isolation, separation and characterisation of dissolved organic matter.Environ Sci Process Impacts, 17 (9), 1531-1567. doi:10.1039/c5em00223k

Shalev, N., Lazar, B., Kobberich, M., Halicz, L., \& Gavrieli, I. (2018). The chemical evolution of brine and $\mathrm{Mg}$-K-salts along the course of extreme evaporation of seawater-an experimental study.Geochimica et Cosmochimica Acta, 241 , 164-179.

Shin, H. S., Hong, K. H., Lee, M. H., Cho, Y. H., \& Lee, C. W. (2001). Fluorescence quenching of three molecular weight fractions of a soil fulvic acid by UO2(II). Talanta, 53 (4), 791-799. doi:10.1016/s00399140(00)00567-1

Singh, S., Inamdar, S., \& Mitchell, M. (2015). Changes in dissolved organic matter (DOM) amount and composition along nested headwater stream locations during baseflow and stormflow. Hydrological Processes, 29 (6), 1505-1520. doi:10.1002/hyp.10286

Stedmon, C. A., \& Bro, R. (2008). Characterizing dissolved organic matter fluorescence with parallel factor analysis: a tutorial.Limnology and Oceanography: Methods, 572-579.

Stedmon, C. A., Markager, S., \& Bro, R. (2003). Tracing dissolved organic matter in aquatic environments using a new approach to fluorescence spectroscopy. Marine Chemistry, 82 (3-4), 239-254. doi:10.1016/s03044203(03)00072-0

Waiser, M. J., \& Robarts, R. D. (2000). Changes in composition and reactivity of allochthonous DOM in a prairie saline lake.Limnology and Oceanography, 45 (4), 763-774.

Wang, X., Cai, Y., \& Guo, L. (2010). Preferential removal of dissolved carbohydrates during estuarine mixing in the Bay of Saint Louis in the northern Gulf of Mexico. Marine Chemistry, 119 (1-4), 130-138. doi:10.1016/j.marchem.2010.01.006

Wang, X., Goual, L., \& Colberg, P. J. (2012). Characterization and treatment of dissolved organic matter from oilfield produced waters.Journal of Hazardous materials, 217-218, 164-170. doi:10.1016/j.jhazmat.2012.03.006

Weber, T., Allard, T., \& Benedetti, M. F. (2006). Iron speciation in interaction with organic matter: Modelling and experimental approach.Journal of Geochemical Exploration, 88 (1-3), 166-171. 
doi:10.1016/j.gexplo.2005.08.030

Wu, F. C., \& Tanoue, E. (2001). Geochemical characterization of organic ligands for copper(II) in different molecular size fractions in Lake Biwa, Japan. Organic Geochemistry, 32 (11), 1311-1318. doi:10.1016/s01466380(01)00094-8

Wu, J., Zhang, H., He, P. J., \& Shao, L. M. (2011). Insight into the heavy metal binding potential of dissolved organic matter in MSW leachate using EEM quenching combined with PARAFAC analysis. Water Research, 45 (4), 1711-1719. doi:10.1016/j.watres.2010.11.022

Wu, J., Zhang, H., Yao, Q.-S., Shao, L.-M., \& He, P.-J. (2012). Toward understanding the role of individual fluorescent components in DOM-metal binding. Journal of Hazardous materials, 215 , 294-301.

Xiping, Z. (2008). Impact of organics in bittern on the quality of BaSO_4 products [J]. Inorganic Chemicals Industry, 11,3 .

Xu, H., \& Guo, L. (2017). Molecular size-dependent abundance and composition of dissolved organic matter in river, lake and sea waters. Water Research, 117 , 115-126. doi:10.1016/j.watres.2017.04.006

Xu, H., Guo, L., \& Jiang, H. (2016). Depth-dependent variations of sedimentary dissolved organic matter composition in a eutrophic lake: implications for lake restoration. Chemosphere, 145, 551-559.

Xu, H., Yan, M., Li, W., Jiang, H., \& Guo, L. (2018). Dissolved organic matter binding with Pb(II) as characterized by differential spectra and 2D UV-FTIR heterospectral correlation analysis. Water Research, 144 , 435-443. doi:10.1016/j.watres.2018.07.062

Xu, H., Zou, L., Guan, D., Li, W., \& Jiang, H. (2019). Molecular weight-dependent spectral and metal binding properties of sediment dissolved organic matter from different origins. Science of the Total Environment, 665 , 828-835. doi:10.1016/j.scitotenv.2019.02.186

Yamashita, Y., \& Jaffe, R. (2008). Characterizing the interactions between trace metals and dissolved organic matter using excitation- emission matrix and parallel factor analysis. Environmental Science 83 Technology, 42 (19), 7374-7379.

Yang, K., Zhang, Y., Dong, Y., \& Li, W. (2017). Selectivity of solid phase extraction for dissolved organic matter in the hypersaline Da Qaidam Lake, China. Environmental Science-Processes 85 Impacts, 19 (11), 1374-1386. doi:10.1039/c7em00263g

Yang, K., Zhang, Y., Dong, Y., Nie, Z., \& Li, W. (2017). Comparative Study of Solid-Phase Extraction of Dissolved Organic Matter from Oilfield-Produced Brine by Different Sorbents. Environmental Engineering Science, 34 (9), 675-686. doi:10.1089/ees.2016.0488

Yang, X., Meng, L., \& Meng, F. (2019). Combination of self-organizing map and parallel factor analysis to characterize the evolution of fluorescent dissolved organic matter in a full-scale landfill leachate treatment plant. Science of the Total Environment, 654 , 1187-1195.

Yu, G. H., Wu, M. J., Wei, G. R., Luo, Y. H., Ran, W., Wang, B. R., . . . Shen, Q. R. (2012). Binding of organic ligands with $\mathrm{Al}(\mathrm{III})$ in dissolved organic matter from soil: implications for soil organic carbon storage. Environmental Science and Technology, 46 (11), 6102-6109. doi:10.1021/es3002212

Zhang, D., Pan, X., Mostofa, K. M., Chen, X., Mu, G., Wu, F., . . . Fu, Q. (2010). Complexation between $\mathrm{Hg}$ (II) and biofilm extracellular polymeric substances: an application of fluorescence spectroscopy.Journal of Hazardous materials, 175 (1-3), 359-365. doi:10.1016/j.jhazmat.2009.10.011

Zheng, M. (2011). Resources and eco-environmental protection of salt lakes in China. Environmental Earth Sciences, 64 (6), 1537-1546. 

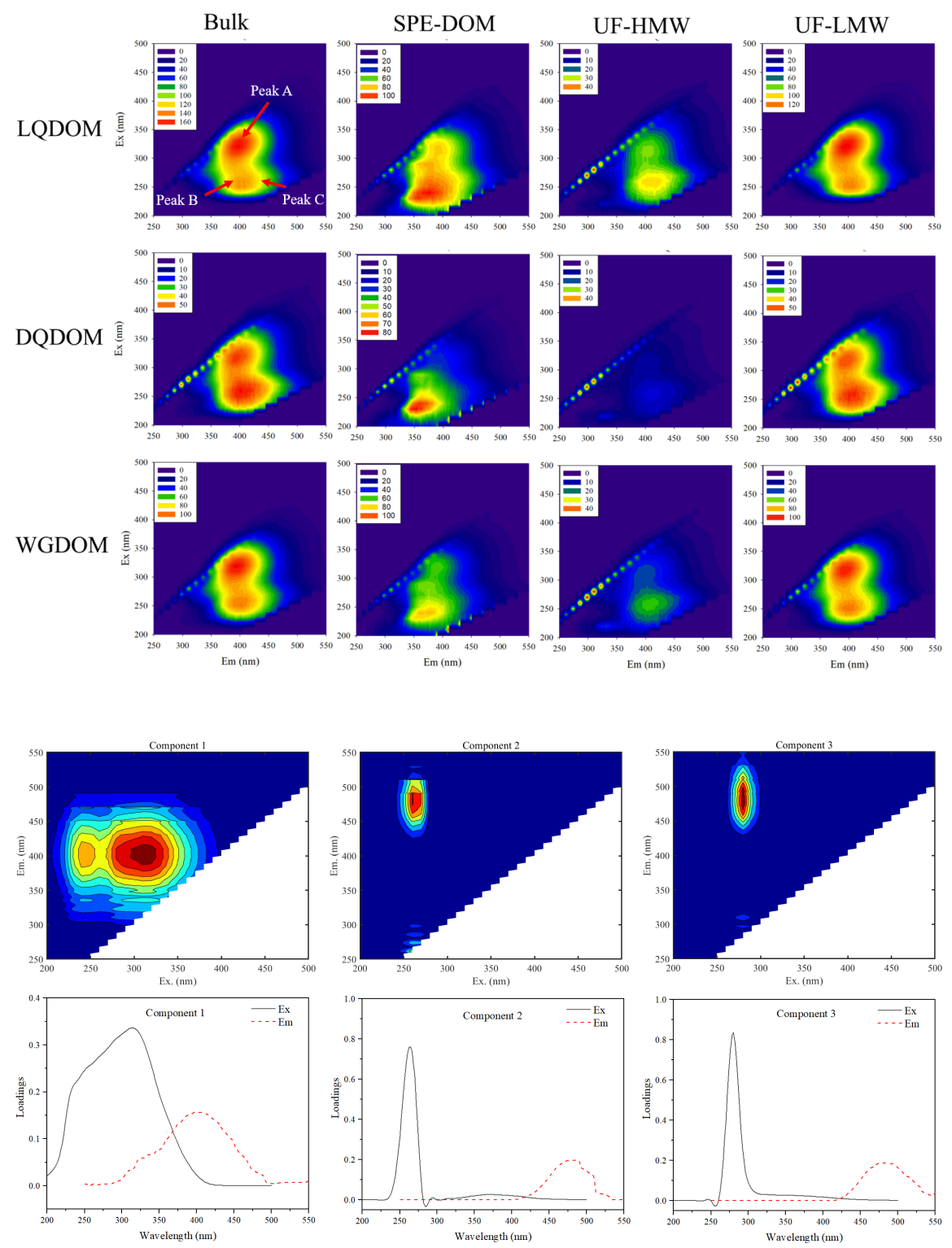

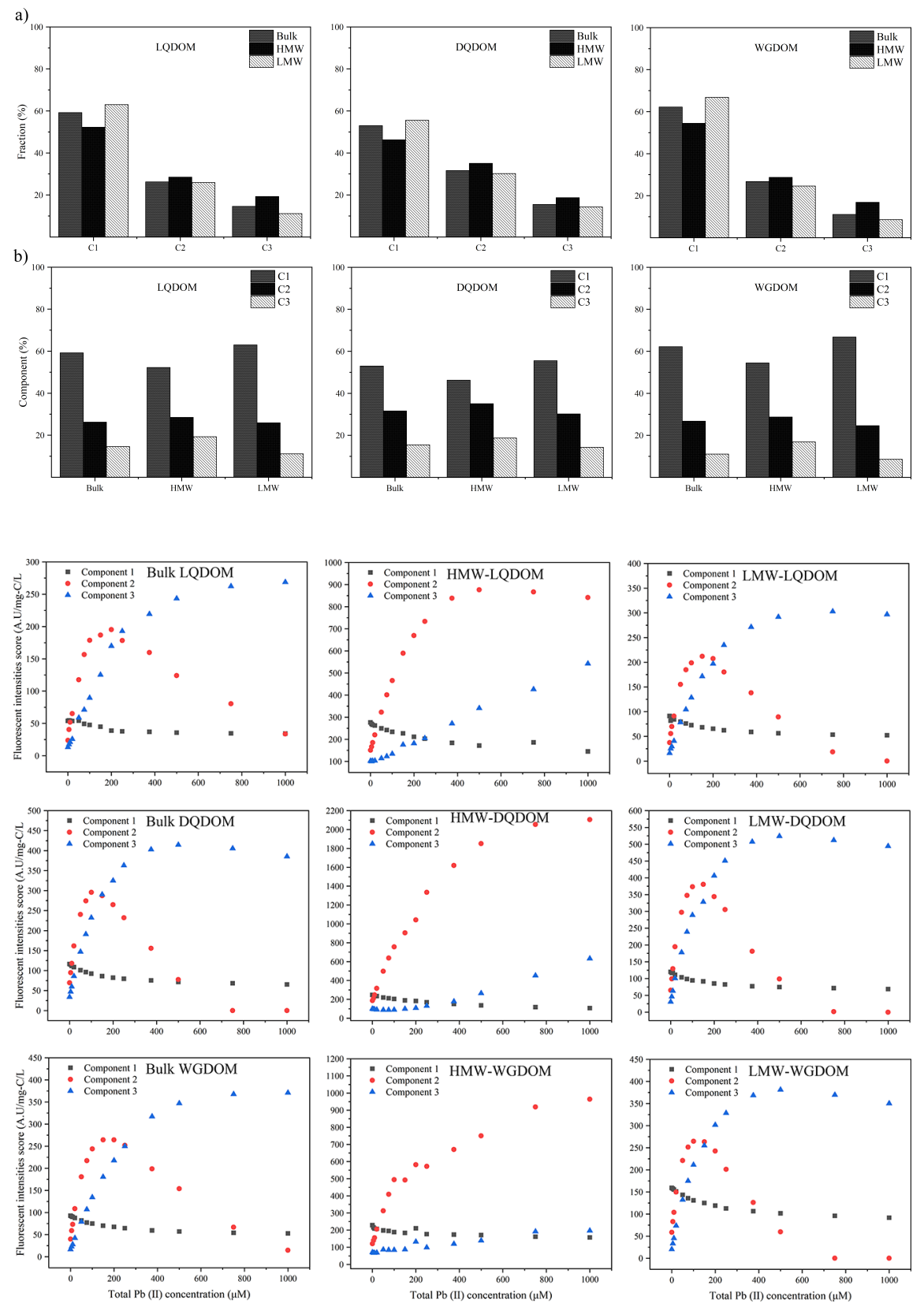

\section{Hosted file}

Table 1.docx available at https://authorea.com/users/338287/articles/464332-metal-bindingby-dissolved-organic-matter-in-hypersaline-water-a-size-fractionation-study-usingdifferent-isolation-method

\section{Hosted file}

Table 2.docx available at https://authorea.com/users/338287/articles/464332-metal-bindingby-dissolved-organic-matter-in-hypersaline-water-a-size-fractionation-study-usingdifferent-isolation-method 